\title{
Patient Artifact
}

National Cancer Institute

\section{Source}

National Cancer Institute. Patient Artifact. NCI Thesaurus. Code C87028.

An artifact resulting from a problem with the patient. 